\title{
Media and Information Literacy (MIL) Competency Assessment of Teaching Personnel at the University of the Assumption
}

\author{
Cris M. Balingit
}

\begin{abstract}
This study titled, Media and Information Literacy (MIL) Competency Assessment of Teaching Personnel within the University of the Assumption was conducted to assess the level of media and information literacy competency of the teachers in the MIL components of Access, Evaluation, and Creation. Moreover, this study attempted to correlate the significant difference between the level of every competency in relation to the age, gender, and the subject taught of the respondents.
\end{abstract}

The objectives were answered through the use of a standards-based test released by UNESCO to assess the media and information literacy of teachers in the 21st-century. Results have found that all components competencies in MIL of the teaching personnel fall under the intermediate level category. In addition, it was found out that there is a significant relationship between the respondents' age and subject area of expertise to the MIL competencies

Findings of this study may help the school administrators to enhance the teachers' media and information literacy in the $21^{\text {st }}$ century.

Keywords - media, information, literacy, access, evaluation, creation.

\section{INTRODUCTION}

"If we teach today's students as we taught yesterday's, we rob them of tomorrow."

- John Dewey

According to United Nations Educational, Scientific, and Cultural Organization (UNESCO), education is considered as a fundamental human right and essential for the exercise of all other human rights. That mission statement is the cornerstone upon which schools and universities are working continuously to build the best pedagogical strategies for today's learners.

Media and information literacy (MIL) has become an essential element in today's pedagogy in preparing critical thinkers for the 21st-century learners. According to Cant et al. (2012), the days of a one-dimensional offering of knowledge to a passive audience is long gone. They added that due to the technological advancement of today's students they are more informed and tech-savvy.

UNESCO defines media and information literacy as the ability of the users to use, analyse, access, evaluate, and interpret messages from different media sources. It builds

Cris M. Balingit, Faculty Member, School of Arts \& Sciences, University of the Assumption understanding in the society as people can extend their skills as well as self-expressionin the broader environment. The role of media literacy is to help people become competent, to be critical thinkers, and literate to all media formats as they can control and filter the information and messages they encounter.

In the Media and Information Literacy Curriculum for Teachers, UNESCO has established the core competencies that teachers are expected to acquire and demonstrate to provide what the overall expected outcomes should be. One of these core competencies is to become media and information literate.

Media literacy is a form of widening the scope of traditional knowledge into new ways of interacting and understanding information through the avenue of moderntechnology-driven media. Generally, it is defined as the ability to access, analyse, evaluate and create media in a variety of formats (Center for Media Literacy, 2017). Information dissemination today is no longer limited to print media, radio, or television but it is now also continuously delivered through the information superhighway, the internet. To meet this paradigm shift, educators must become media literate because their students are already tech-savvy. Instructors need to realize that expertise in media and information literacy resources is a necessary professional competency required to educate the 21 st-century learners.

As an educational field, Media Literacy is dedicated to teaching the skills associated with media literacy, according to the National Association for Media Literacy Education (2017).Defined societal normative behaviours include the followingskill sets: a purposeful student, a responsible citizen, a productive worker, and/or a competent and conscientious consumer. Educators draw upon the motivational theory of expectancy in teaching media literacy. The underlying tenet is that individuals need to develop expertise with understanding the marketing psychology behind the increasingly sophisticated information and entertainment media that confront on a multi-sensory level, affecting the way the consumer thinks, feels, and behaves.

Bill Walsh stated in the Center for Media Literacy website that years ago, an older teacher pointed out to him a new technology which would quite literally revolutionize education. Indeed, a photocopier can turn every teacher into a publisher. A video camera can turn every educator into a movie producer. A home computer can turn every classroom presentation into a 
multi-media presence in homes and libraries all around the world.

Buckminster Fuller created the "Knowledge Doubling Curve"; he noticed that until 1900 human knowledge doubled approximately every century. By the end of World War II, knowledge was doubling every 25 years. Today things are not as simple as different types of knowledge have different rates of growth. For example, nanotechnology knowledge is doubling every two years and clinical knowledge every 18 months. But on average human knowledge is doubling every 13 months. According to IBM, the build out of the "internet of things" will lead to the doubling of knowledge every 12 hours.

Dr. Mary Kalantzis, a professor in the Department of Education Policy, Organization and Leadership at the University of Illinois said in her Grammar of Multimodality: "Among significant developments, we see proliferation of still and moving image as modes of expression,displacing or augmenting messages that would once have been expressed mainly in oral or written language. We also witness a dramatic extension of the sites of writing and reading, and in new and hybrid genres."

Also, Dr. Bill Cope added in his Learning Assessment in the Era of Technology-Mediated Learning that educational technologies are a part of the equation. However, the transformation is fundamental, pedagogical, rather than technological. Technologies have the capacity to support pedagogical change, but equally to revive and fossilize old pedagogies.

By focusing on teachers, UNESCO hopes to capitalize on the potential multiplier effect. That is, media and information literate teachers acting as change agents by helping their students to acquire knowledge, competencies, and values in the educational domain of media and information literacy which, in turn, leads to societies that are media and information literate.

Meanwhile, according to the learning resource portal of the Department of Education (deped.gov.ph) teachers will prioritize literacy by learning and teaching media and information literacy through a constructivist approach.Students will thenbecome competent consumers and producers of information and media resources; in addition, they will develop digital citizenship and lifelong learning.

According to Wilson \& Jolls (2015), teachers today need the opportunity to learn about media and information literacy, to develop pedagogical approaches for exploring new MIL technologies, and to develop a strategy in analysing and evaluating of media content and information available in today's world.

With all these concerns about student preparedness in the $21^{\text {st }}$ century, media and information providers are affecting the education systems. Therefore,media and information literacy is essential for today's teachers. In this study, the researcher used the MIL Assessment Framework 02013 created by UNESCO. According to UNESCO, the framework fosters lifelong initiatives by building on the relationship between information, media, digital and ICT literacies along with societal transformation, education, workforce, policy and decision making process, economic growth and democracy. It also assesses the country's readiness and competencies regarding the media and information literacy of citizens in particular teachers in service and in training. UNESCO added that in order to teach and prepare young people for tomorrow's world, educators themselves need to be empowered with their training needs addressed and supported.

The framework presented by UNESCO (2013) for MIL has three (3) components: Access, Evaluation, and Creation.

The first component is Access. In this component the individual should have the ability to access, retrieve, and store information and media content using appropriate technologies. It also includes the ability of an individual to recognize the need for information, media content and knowledge and be able to identify useful data and media content from all sources and formats including but not limited to print, audiovisual and digital to satisfy the need. Retrieval in this component means the ability to locate and obtain the needed information. (UNESCO, 2013)

Evaluation is the second component and it is defined as the ability of the user to understand, critically analyse and evaluate information, media content, the work and functions of media and information institutions, within the context of universal human rights and fundamental freedoms. Moreover, it also includes the ability of the user to determine the reliability and credibility of the author or producer of the information being accessed. It also involves evaluating the quality of the information content in terms of accuracy, relevance, currency, reliability and completeness. Lastly, it also includes the mastery of technical skills of organizing, selecting and synthesizing media and information. (UNESCO 2013)

Finally, the third MIL component is Creation. It is defined as the ability to master the production know-how information, media content and new knowledge and effectively communicate with others. In other words, the user should know how to create and deliverfurther information before releasing them for public consumption. This component also requires knowledge about the media and information, Furthermore, Creation requires ethics in attitude and values in using media and information. This means that the user after creating new information should know how to give credits to the copyrighted materials.

This study used the following components to assess the level of media and information literacy of the teaching personnel in a private university in Pampanga as the basis for developing a faculty media and information literacy program in the institution

\section{Statement Of The PRoblem}

This study aims to assess the level of media and information literacy competencies of the instructors among teaching personnel in a private university.

Specifically, it seeks answers to the following questions:

1. What is the demographic profile of the respondents in terms of their age, gender, and subject taught? 
2. What is the level of media and information literacy competencies and skills of the respondents in terms of their Access, Evaluation, and Creation?

3. Is there a significant relationship between the respondents' profile and their level of MIL competencies?

\section{RESEARCH HYPOTHESIS}

There is no significant relationship between the respondents' profile and their level of MIL competencies.

\section{SIGNIFICANCE OF THE STUDY}

This study aimed to assess the level of media and information literacy competencies and skills of the teachers in the university as a basis for developing a faculty media and information literacy training program.

The results of the survey and findings of the study are designed to:

- identify the media and information literacy competencies and skills among teachers in the university.

- determine whether the teachers needed any further media and information literacy programs or training.

- provide information on whether there is a need for additional resources or a change of strategy in the pedagogy of the teachers.

This study also provides a snapshot of the levels of knowledge of media and information literacy as well as information on the current needs of these teachers with four recommendations for meeting the goal of MIL mastery for all teachers.

\section{Methodology}

This study employed a descriptive-correlational type of research. On the one hand, the descriptive part of the study is two-fold. First, it describes the respondents' profile, and secondly, it assesses their level of competencies in Media and Information Literacy. On the other hand, this study is correlational in a way that the researcher used the other variables in order to determine their significant relationship in terms of the level of the respondent's competencies vis-à-vis their gender, age and subject taught.

\section{PARTICIPANTS AND SAMPLING TEChNIQUe}

The current study was conducted by surveying the teaching personnel from the University of the Assumption to assess their level of competencies in media and information literacy. Respondents are currently teachers at the University of the Assumption in the academic year 2017-2018. Out of a population of over 200, a representative sample of 119 teachers from four different departments: grade school $(n=28)$, junior $(n=37)$ and senior high school $(n=35)$ and college $(n=19)$ participated in the survey. Among the respondents, 85 (71.4\%) were female while $34(28.6 \%)$ were male. The sample populationhas an age range from 20-68 with more than half of the respondents teaching General Education subjects (51.3\%), $36(30.3 \%)$ teaching both professional and general education subjects and 22 respondents $(18.5 \%)$ teaching professional courses.

\section{INSTRUMENTS}

A standards-based survey from UNESCO was used for the data collection process of this study. The first section was a demographic profile wherein the respondents were asked to include their age, gender, and the subject/s areas taught. The second part of the questionnaire is a Likert-type scale measuring the level of the MIL competencies of the respondents.

\section{DATA Gathering Procedure}

The researcher sent an authorized formal participation request letter to the heads of every department explaining the need for the survey and its purpose. When the request was affirmed by the department heads, the researcher forwarded the copies of the questionnaire to every department. The teachers were then told of the scope of the project and were invited to participate voluntarily in anonymity in answering the survey questionnaire.

Data were collated, organized and subjected to appropriate statistical treatment. The data were analyzed using SPSS (Statistical Package for the Social Sciences\}. For the respondent's profile and level of the MIL competencies, the researcher used the frequency, mean and standard deviation.

In interpreting the levels of MIL competencies of the respondents the following reasoned scale was used:

$$
\begin{array}{ll}
1.00-1.74 & \text { - None } \\
1.75-2.50 & \text { - Beginner } \\
2.51-3.25 & \text { - Intermediate } \\
3.26-4.00 & \text { - Advanced }
\end{array}
$$

Moreover, One-way ANOVA and Independent T-Test were used to determine the significant relationship between the respondents' profile and the level of MIL competencies of the respondents.

\section{FINDINGS OF THE STUDY}

This section presents the results of the study. It contains the demographic profile of the respondents, the level of their MIL competencies, and the significant relationship of the respondents' profile to the level of MIL competencies.

Table 1 shows the demographic profile of the respondents which includes their ages, gender, and subject taught. It illustrates that a majority of the respondents' age range is from 20-40 years old with a gender dispersion that is primarily female with $71.4 \%$. Lastly, in terms of the subject taught by the respondents, it shows that the majority of them teach general education course. 
TABLE I:. DEMOGRAPHIC PROFILE OF THE RESPONDENTS

\begin{tabular}{lcc}
\hline Age & No. of Respondents & Percentage \\
\hline $20-40$ & 83 & 69.7 \\
$41-60$ & 24 & 28.6 \\
61 -above & 2 & 1.7 \\
\hline Total & 119 & 100 \\
\hline Gender & No. of Respondents & Percentage \\
\hline Male & 34 & 28.6 \\
Female & 85 & 71.4 \\
\hline Total & 119 & 100 \\
& & Percentage \\
\hline Subject Taught & No. of Respondents & 18.5 \\
\hline Professional Course & 22 & 51.3 \\
General Education & 61 & 30.3 \\
Gen Ed and Prof & 36 & 100 \\
Course & 119 &
\end{tabular}

TABLE II LEVEL OF MIL COMPETENCIES IN TERMS OF ACCESS, EVALUATION,AND CREATION

ACCESS

\begin{tabular}{|c|c|c|c|}
\hline Competency & Mean & $\begin{array}{c}\text { Std } \\
\text { Deviation }\end{array}$ & $\begin{array}{c}\text { Verbal } \\
\text { Interpretation }\end{array}$ \\
\hline $\begin{array}{l}\text { Articulation } \\
\text { Search } \\
\text { Access } \\
\text { Retrieval }\end{array}$ & $\begin{array}{l}3.14 \\
2.98 \\
3.04 \\
2.98\end{array}$ & $\begin{array}{l}0.50 \\
0.50 \\
0.51 \\
0.54\end{array}$ & $\begin{array}{l}\text { Intermediate } \\
\text { Intermediate } \\
\text { Intermediate } \\
\text { Intermediate }\end{array}$ \\
\hline \multicolumn{4}{|c|}{ EVALUATION } \\
\hline Competency & Mean & $\begin{array}{c}\text { Std } \\
\text { Deviation }\end{array}$ & $\begin{array}{c}\text { Verbal } \\
\text { Interpretation }\end{array}$ \\
\hline $\begin{array}{l}\text { Understanding } \\
\text { Assessment } \\
\text { Evaluation } \\
\text { Organization }\end{array}$ & $\begin{array}{l}3.09 \\
2.61 \\
2.95 \\
2.94\end{array}$ & $\begin{array}{l}0.51 \\
0.50 \\
0.58 \\
0.59\end{array}$ & $\begin{array}{l}\text { Intermediate } \\
\text { Intermediate } \\
\text { Intermediate } \\
\text { Intermediate }\end{array}$ \\
\hline \multicolumn{4}{|c|}{ CREATION } \\
\hline Competency & Mean & $\begin{array}{c}\text { Std } \\
\text { Deviation }\end{array}$ & $\begin{array}{c}\text { Verbal } \\
\text { Interpretation }\end{array}$ \\
\hline $\begin{array}{l}\text { Creation } \\
\text { Communication } \\
\text { Participation } \\
\text { Monitoring }\end{array}$ & $\begin{array}{l}2.90 \\
3.10 \\
2.93 \\
2.85\end{array}$ & $\begin{array}{l}0.58 \\
0.51 \\
0.64 \\
0.67\end{array}$ & $\begin{array}{l}\text { Intermediate } \\
\text { Intermediate } \\
\text { Intermediate } \\
\text { Intermediate }\end{array}$ \\
\hline
\end{tabular}

Table 2 represents the respondents' level of competencies in MIL's constituent components: Access, Evaluation, and Creation. It clearly shows that all competencies in each component fell under the intermediate level. While the respondents have an intermediate level of knowledge and skills acquired from a prior knowledge, there are gaps in certain areas. Consistently, the result of the standard deviation reflects the respondents' level of MIL competency ranges from .50 - .67. This narrow range of deviation indicates that the respondents are strictlyhomogeneous in terms of their MIL competency.

In the Access component, articulation has the highest mean $(\mathrm{m}=3.14)$ while the lowest mean $(\mathrm{m}=2.98)$ is recorded in the search and retrieval competencies. This signifies that the respondents have adequate knowledge in recognizing the need for the information and media content to be used in the facilitation of learning. However, in terms of search and retrieval, it is noticeable that some of the respondents are not confident in their use of different media platforms to locate and to retrieve the information they seek.

In the Evaluation component of MIL, it was observed that "Understanding," highest mean $(\mathrm{m}=3.09)$, is quite lower when compared to "Articulation," highest mean $(\mathrm{m}=3.14)$, of the Access component. It is evident that the respondents are more confident in articulating in the Access component compared to understanding in the Evaluation component of MIL.

Another component of MIL is Creation. This component is the ability of the respondents to create, utilize, and monitor information and media content. Communication competency has the highest mean $(\mathrm{m}=3.10)$ while the Monitoring competency has the lowest mean $(\mathrm{m}=2.85)$ This implies that some of the respondents may not have the capability of using monitoring abilities or mechanisms and policies for a periodical assessment of the effectiveness of the intended impact of created and distributed information, media content and knowledge as well as use existing media and other information providers.

Overall, the Access component appears to have the most frequently used skills by the respondents with the highest meanwhen compared to Evaluation and Creation. It denotes that both male and female educator's access messages through the use of different media format and they are able to collect relevant and useful information and understand its significance efficiently.

TABLE III. RELATIONSHIP BETWEEN THE RESPONDENTS’ AGE AND THE LEVEL OF MIL COMPETENCY

\begin{tabular}{|c|c|c|c|c|c|c|}
\hline Component & $20-40$ & $\begin{array}{l}\text { MEAN } \\
41-60\end{array}$ & 61 - above & $\mathbf{F}$ & p-value & Decision \\
\hline Access & 3.09 & 2.97 & 2.19 & 4.48 & 0.013 & Rejected \\
\hline Evaluation & 2.04 & 2.77 & 2.97 & 5.83 & 0.004 & Rejected \\
\hline Creation & 2.40 & 2.77 & 3.03 & 3.93 & $0.022 *$ & Rejected \\
\hline
\end{tabular}


Table 3 presents the relationship of the respondents' level of MIL competency and their age. It reveals that the age of the teaching personnel has a significant relationship to the level of their MIL competency. All components have p-value which is less than .05. The post hoc test signifies that 61 - above differs significantly from the respondents whose ages range from 20-60 years old. This demonstrates that the younger generations have a higher access to media and information literacy compared to older generations. As stated and supported by the National Association for Media literacy education (NAMLE) the purpose of media literacy education is to help individuals of all ages develop the habits of inquiry and skills of expression that they need to be critical thinkers, effective communicators and active citizens in today's world.

TABLE IV.RELATIONSHIP BETWEEN THE RESPONDENTS’ GENDER AND THE LEVEL OF MIL COMPETENC

\begin{tabular}{lllllll}
\hline \multirow{2}{*}{ Component } & \multicolumn{2}{c}{ Male } & \multicolumn{2}{c}{ Female } & p-value & Decision \\
& Mean & SD & Mean & SD & Accepted \\
Access & 3.06 & 0.39 & 3.03 & 0.49 & 0.075 & Accepted \\
Evaluation & 2.93 & 0.46 & 2.87 & 0.49 & 0.540 & Rejected \\
Creation & 2.97 & 0.41 & 2.94 & 0.60 & $0.028^{*}$ & r
\end{tabular}

The Table 4 exhibitreveals that the Access \& Evaluation components of MIL competency do not have any significant relationship to the respondents' gender. However, it can be observed that the Creation component of MIL does indicate a significant relationship to the gender of the respondents. component while the male scored his lowest mean 2.93 along with the female 2.87 under Evaluation. Statistically, males have a higher level of competencies in creating, utilizing, and monitoring information and media content in the Creation component thus rejecting the Null Hypothesis.

Both the male with a high mean score of 3.06 and the female with a high mean score 3.03 are located under the Access

TABLE V.RELATIONSHIP BETWEEN THE RESPONDENTS' LEVEL OF MIL COMPETENCY AND THEIR SUBJECT/S AREAS

\begin{tabular}{|c|c|c|c|c|c|c|}
\hline Component & $\begin{array}{c}\text { Professional } \\
\text { Course }\end{array}$ & $\begin{array}{c}\text { MEAN } \\
\text { General } \\
\text { Education }\end{array}$ & $\begin{array}{c}\text { Prof. Course \& } \\
\text { Gen. Ed }\end{array}$ & f & p-value & Decision \\
\hline Access & 2.83 & 3.04 & 3.15 & 3.40 & $0.037^{*}$ & Rejected \\
\hline Evaluation & 2.64 & 2.92 & 3.02 & 4.63 & $0.012^{*}$ & Rejected \\
\hline Creation & 2.70 & 2.97 & 3.09 & 3.42 & $0.036^{*}$ & Rejected \\
\hline
\end{tabular}

Results reported in Table 5indicate that all of the components of MIL competency have a significant relationship to the subject field of the respondents. In this table, the means of the respondents who are teaching professional courses and general education subjects are higher when compared to the teachers who are instructing only professional classes and general education. The highest mean of 3.15 among the three groups occurs in the Professional Course and General Education sector in the Access component. Among the respondents, only one focus area has the highest mean of 3.04 which is also under the Access component of MIL. In comparing Table 5 results with Table 2, it becomes self-evident that the Access component has the highest mean in the MIL competency of the respondents.

Meanwhile, the lowest mean that may be observed on the respondents' MIL competency is on the Evaluation component with a mean of 2.64.One conclusion drawn from this data is that in this component the respondents may have gaps in understanding, assessing and evaluating information and media

\section{DisCUSSION}

Media literacy is an emerging pedagogical field of the educational learning process. It is defined as a set of perspectives that we actively use when we expose ourselves to media in order to interpret the meaning of messages which we encounter (W. Potter, 2008). It is a skill we take for granted, but like all skills, it can be improved (S. Baran, 2010). Today, more than ever before, people have the ability to access, evaluate and create information. Because of the vast amount of information that is presented through the various mediums people today suffer from an information glut. In turn, their compositions are drawn from a variety of sources, but later they realize that media is imperfect for making unassailable conclusions. That's why analysis is essential by looking beneath the surface of mass media to become perspectively literate thus making findings of 
fact based on the person's understanding of the complexities of the material being presented,

The results of our survey have shown that most of the responding teaching personnel in the university have an age range of 20-40 years old and most of them are female. In terms of subject matter, almost all of them are teaching general education courses.

According to UNESCO, Media and Information Literacy plays a prominent role in their list of fundamental individual rights. It opens a new horizon for every individual to exercise their rights to freedom of opinion, expression, and access to information. Thus, MIL covers a vast range of competencies. It entails finding and evaluating the credibility of online information, through to creating new knowledge to shape young people's minds.

In the current study, the level of the respondents in the competencies of all MIL components (Access, Evaluation, Creation) fell under the intermediate level. This means all MIL competencies of the teaching personnel in the university have a reasonable level of knowledge and skills acquired from practice and training, but there are gaps in some specific areas.

In the Access component, all results fell into the intermediate level; it was observed that the respondents are having difficulty in searching and retrieving the information needed by them. In this study, searching is defined as the users' search strategy to find appropriate tools to be used in classroom instruction, which includes media content and providers. An extrapolation of the data revealed that the information sources of the respondents are insufficient to find the proper tools to be used in their classroom. Moreover, it was also observed that the respondents recorded their retrieval strategy as one of the lowest means in the access component. Retrieval in this study is defined as the ability to select, organize and hold onto the obtained information and media content for class discussion by using appropriate technologies and tools. Their low score reveals that even though they have searched for the needed information, the respondents may have difficulty when trying to retrieve the access information. Some online data may require a security password in order to access it or a subscription. Moreover, some information may not be available in the local setting of the user or in the case of a business or school, blocked by being on a blacklist.

There is direct correlation between the low mean scores in the search and Retrieval competencies in the Access component and the equally low mean scores in the Assessment competency in the Evaluation component This competency is defined as the ability of the users to assess or evaluate the quality of the materials accessed in terms of authorship, relevance, reliability, completeness, accuracy, timeliness, and coverage. This deficiency can be linked to the respondents either not having a rubric or a primary assessment tool for the evaluation of media content information, media, and other information providers.

The last component of the survey is the Creation. In this component, it was observed that the Monitoring competency has the lowest mean. Monitoring is defined as the ability of the users to apply or establish monitoring methods or mechanisms and policies or instruments for the periodical assessment of the effectiveness of the intended impact. In other words, after creating new information and delivering to their intended audience, the respondents do not have any tools to measure the impact or the effectiveness of the message.

Another objective of this study is to determine the significant relationship between the respondents' profile to their MIL competencies.

In terms of the respondents' age, it was found out that there is a significant relationship to the level of MIL competencies of the respondents. The study revealed that those of the younger generation are more media and information literate when compared to the older respondents. A quote from the booklet, Media Education, Make it Happen, states it most cogently, "Young people are immersed in media, moving beyond geographical and regulatory boundaries as they access, absorb, communicate, create and repurpose media content." In this technological age, people live in a world dominated by communications technology; wherein almost everything is affected by or transformed by technology. This pattern offers significant opportunities for introducing MIL to older people. Most of them rely on the traditional media platforms such as the print and broadcast media. This study is supported by the European Older People's Platform (2005) wherein the respondents aged 55 and above records low level of media and information literacy because of their limited exposure to media and technology.

In another aspect of the study, gender results yielded no significant relationship between the respondents' gender to the level of MIL competencies. However, it was statistically determined that there is a significant relationship between the respondent's gender to the MIL Creation component. It was concluded that males are more skilled in terms of creating, utilizing and monitoring information and media content. This result is unique when compared with the report of Gender and Development Committee of National Statistics Office in 2008; it was found in the Functional Literacy Education and Mass Media Survey that functional literacy rate among females is higher than among males. The referenced survey gathers information on basic and functional literacy status of the population, the education skills qualifications, and exposure of the population to mass media. According to darlingmagazine.org, an individual who has a high level of Creation competency is more apt to recognize production techniques used to grab viewer's attention and also have the potential to start telling new stories. In the study of Taylor and Dalal (2017), analysis of data collected provided strong indications of gender differences. Female respondents appeared to be more discerning than males in evaluating online sources. However, males seemed to be more confident in the credibility and accuracy of the results returned by search engines.

In addition, it was found out that there is a significant relationship between the respondents' subject area of expertise 
to the MIL competencies. It was observed that the educators instructing both professional courses and general education subjects have distinct competencies compared with those educators who are teaching only either professional courses or general education subjects. Scull and Kupersmidt (2011) mentioned in their study that regardless of the subject taught by the teachers, it is vital to recognize that media and information literacy is a critical part of education in today's world. They added that media and information literacy competency, even for trained and professional educators is effective in changing attitudes, knowledge, and self-reported behaviour not only for them but also for the learners.

Media and information literacy are established as an instructional or pedagogical strategy and learning across the different subject areas.

\section{RECOMMENDATIONS}

Based on the findings of this research paper, the following recommendations are endorsed:

1. Even though the educators are on the intermediate level of media and information literacy in accessing, evaluating, and creating information; they still need to develop their tech-savvy skills to be able to pass their expertise on to students on MIL-related issues. The role of education is to impart information that becomes knowledge. Technology is an integral part of education in the 21st-century. Today's educators must now focus more on raising awareness and improvement of ethics and tools for deepening the understanding of media and information literacy..

2. It is essential that educators research different media platforms including print (books, journals, magazine), broadcast media (TV, radio, films) and new media formats (Online newspapers, online journals, social media), in order to locate and search the best information or materials to be used in the classroom.

3. Educators are required to have training in media literacy in order to serve as skillful21st-century educators. Moreover, trained instructors who are MIL advanced are to share their knowledge and expertise with their colleagues.

4. It is incumbent upon the university's administrators to ensure that the teaching personnel are highly media and information literate in teaching the students. They need to consider that media and information literacy is an essential pedagogy that is not affected by their age or gender.

\section{REFERENCES}

[1] Bailey, G. C., \& Paul, M. A. (2012). Report from the Field: Outcome Evaluation of

the Library Media Program on Information Literacy Skills in Montgomery County Public Schools, Maryland.

[2] Cope, B. Kress, G., Beavis, C., \&Kalantzis, M. (2017). Media Literacy in Foreign Language Edition: Digital and Multimedia Perspectives

[3] Miller, K. (2005). Communication Theories: Perspective, Process, and Contexts (2nd Edition) p.248.

[4] Potter, W.J (2008). Media Literacy (4th Edition).

[5] Thoman, E. \&Jolls, T. (2003). Literacy for the 21st Century: An overview and orientation guide to media literacy education.

[6] Center for Media Literacy (2017). From http:/www.medialit.org/reading-room/what-media-literacy-definitionand -more.

[7] DepEdTambayan (2017). Teaching guide for senior high school on media and information literacy from Depedtambayanph.blogspot.com

[8] Learning Resource Portal Deped.gov.ph.

[9] Mayhew, A. (2014, January 17).Gender gap growing in teaching profession from https://ed.stanford.edu/in-the-media/gender-gap-growing-teaching-profe ssion-cites-thomas-dee-research.

[10] Scull, T., \& Kupersmidt, J. (2012). An Evaluation of a Media Literacy Program Training Workshop for Late Elementary School Teachers. Retrieved February 20, 2018. 